\title{
Reações subjetivas de estudantes da cidade de Tucano- BA às variantes não padrão da concordância verbal ${ }^{1}$
}

\author{
Subjective reactions of students from the city of Tucano- $B A$ to non- \\ standard variants of verbal agreement
}

\author{
Nilton Carlos Carmo Sousa* \\ Escola Municipal João Paulo Fragoso \\ Conceição do Coité, Bahia, Brasil \\ Silvana Silva de Farias Araújo** \\ Universidade Estadual de Feira de Santana \\ Feira de Santana, Bahia, Brasil
}

\begin{abstract}
Resumo: Este artigo com base teórica na Sociolinguística (WEINREICH; LABOV; HERZOG, 2006[1968]) e na Psicologia Social (LAMBERT; LAMBERT, 1968) apresenta as reações subjetivas de estudantes da Educação Básica do município de Tucano, interior da Bahia, Brasil, sobre as variantes não padrão da concordância verbal. Com base em entrevistas e em aplicação de questionários, objetivou-se analisar a avaliação social de normas não padrão da primeira pessoa do plural (P4) e da terceira pessoa do plural (P6). Para isso, foram entrevistados oito estudantes do $6^{\circ}$ ano do Ensino Fundamental Anos Finais, oriundos de espaços geográficos diferentes: quatro da zona rural e quatro da zona urbana. Os resultados indicam que, mesmo havendo características comuns aos dois grupos, a exemplo de os dois estarem matriculados no mesmo ano escolar, estudarem em escolas públicas e terem a mesma faixa etária, a localidade (rural-urbana) condicionou as reações subjetivas, evidenciando os participantes da localidade rural como utentes da língua mais críticos e detentores de uma avaliação sociolinguística mais aflorada.
\end{abstract}

Palavras-chave: Reações subjetivas. Variação na concordância verbal. Educação Básica. Avaliação sociolinguística.

\begin{abstract}
This article with a theoretical basis in Sociolinguistics (WEINREICH; LABOV; HERZOG, 2006 [1968]) and in Social Psychology (LAMBERT; LAMBERT, 1968) presents the subjective reactions of students of Basic Education in the municipality of Tucano, in the interior of Bahia, Brazil, on non-standard variants of verbal agreement. Based on interviews and questionnaires, the objective was to analyze the social assessment of non-standard norms of the first person in the plural (P4) and the third person in the plural (P6). For this, eight students from the 6th year of Elementary School Final Years were interviewed, coming from different geographical spaces: four from the rural area and four from the urban area. The results indicate that, even though there are characteristics common to both groups, such as the two being enrolled in the same school year, studying in public schools and having the same age group, the location (rural-urban) conditioned the sociolinguistic perception, evidencing the rural community participants as more critical language users and holders of a more in-depth sociolinguistic assessment.
\end{abstract}

Keywords: Subjective reactions. Variation in verbal agreement. Basic education. Sociolinguistic assessment.

\footnotetext{
${ }^{1}$ Este artigo apresenta alguns dos resultados da pesquisa de Mestrado de Sousa (2019) realizada no âmbito do Programa de Pós-Graduação em Estudos Linguísticos da Universidade Estadual de Feira de Santana (UEFS) e financiada pela Coordenação de Aperfeiçoamento de Pessoal de Nível Superior (CAPES - Código de Financiamento 001).

* Mestre pelo Programa de Pós-Graduação em Estudos Linguísticos - PPGEL - Universidade Estadual de Feira de Santana (UEFS), Feira de Santana, Bahia, Brasil. E-mail: nccsousa@hotmail.com.

** Professora Titular de Língua Portuguesa da Universidade Estadual de Feira de Santana (UEFS) e do Programa de Pós-Graduação em Estudos Linguísticos (PPGEL/UEFS), Feira de Santana, Bahia, Brasil. E-mail: silvana.uefs.2014@gmail.com.
} 


\section{INTRODUÇÃO}

A variação na concordância verbal pode gerar atitudes negativas (AGUILERA, 2008) ou estereótipos linguísticos (LABOV, 2008[1972]) quando determinados falantes avaliam sua própria língua e a língua do outro. É bastante comum ouvir de falantes nativos do Português Brasileiro, por exemplo, que não sabem falar direito ou que falam tudo errado, ratificando a crença de que o português é homogêneo e de que existe uma única maneira de falar, o que, como se sabe, não é verdade.

É interessante esclarecer que, ao tratar da variação na concordância verbal, pensase nos usos linguísticos não padrão, a exemplo de "Nós bate par ou ímpar e divide" e "Os pneu esvaziou"2. Essas variantes, respectivamente, de P4 e de P6, nem sempre são bem avaliadas e podem gerar preconceito linguístico, advindo da crença de língua única, como mencionado anteriormente.

As crenças interessam não só à Sociolinguística, mas à Antropologia, à Sociologia e à Linguística Aplicada (CYRANKA, 2007), por isso não são fáceis de definir e de estudar. Para se debruçar sobre esse tema, cabe ao pesquisador, primeiramente, lançar olhos para a Psicologia Social e reconhecer o estudo das atitudes enquanto comportamento social pautado em três componentes essenciais, sendo um deles o componente cognitivo, o qual equivale às crenças, que podem ser pensadas como "sociais, individuais e flexíveis" (SABADIN, 2013, p. 63) e definidas como a forma que o mundo e os acontecimentos são percebidos, significados e ressignificados (BARCELOS, 2006, p. 18).

As atitudes $^{3}$ (LAMBERT; LAMBERT, 1968), além de terem o componente cognitivo como essencial, embasam-se nos componentes afetivo (avaliação) e conativo (conduta), podendo ser conceituadas, de acordo com Aguilera (2008, p. 106), como a soma de "[...] crenças, conhecimentos, afetos e tendências a comportar-se de uma forma determinada diante de uma língua ou de uma situação sociolinguística." Para essa autora, que apresenta pensamento semelhante ao de Lambert e Lambert (1968), as atitudes são condicionadas pela cultura e ideologia que constituem a identidade linguística dos falantes de uma língua, podendo ser neutras, positivas ou negativas.

Considerando essa breve explanação a respeito do fenômeno avaliado neste artigo, na próxima seção são apresentados estudos realizados no Brasil sobre a percepção sociolinguística de falantes nativos do Português Brasileiro referente à concordância verbal.

\section{ESTUDOS SOBRE AVALIAÇÃO SUBJETIVA DA CONCORDÂNCIA VERBAL}

\footnotetext{
${ }^{2}$ Dados retirados da pesquisa de Sousa (2019).

${ }^{3}$ É imperioso abordar as atitudes linguísticas porque o componente cognitivo (crenças) é um de seus domínios. Ressalta-se, porém, que, neste artigo, não são abordadas as atitudes linguísticas dos estudantes, mas suas crenças, isto é, suas reações subjetivas ao uso não padrão da concordância verbal.
} 
Os estudos apresentados nesta seção demonstram que a variação na concordância verbal é um fenômeno em destaque no Português Brasileiro, não só quanto à avaliação dos falantes, mas também quanto aos usos linguístico, sendo um dos fenômenos mais estudados no Brasil desde que a Teoria da Variação e Mudança Linguística foi trazida para essa nação.

A partir dessa problemática, para debater a significação da concordância verbal (CV), são apresentados, nesta seção, os trabalhos de Bortoni-Ricardo (2008), Miranda (2014) e Oushiro (2015).

\subsection{BORTONI-RICARDO (2008)}

Bortoni-Ricardo (2008) problematiza o que vem a ser uma comunidade de fala, de modo a apresentar o conceito antes dos estudos sociolinguísticos e depois deles. A autora fez um apanhado dos estudos sobre concordância verbal, discutindo o contato entre línguas e afirmando que a CV não padrão é uma regra variável gradual, pois ocorre ao longo de todo o continuum rural-urbano. Segundo a pesquisadora, a concordância verbal funciona como um indicador e marcador no processo de variação e mudança.

A investigação realizada na pesquisa visou depreender as reações subjetivas à ausência de concordância verbal na terceira pessoa do plural, buscando a percepção do traço em dois grupos de falantes que representam graus de escolarização distintos: estudantes do Ensino Superior e estudantes da Educação Básica - Supletivo, sendo a amostra composta por 48 falantes, 24 universitários e 24 da Educação Básica.

O resultado da pesquisa mostrou que os falantes distinguem as duas normas (padrão e não padrão), assim como confirmou que a norma padrão é avaliada como sendo mais correta que a não padrão e que o fator escolaridade é importante, pois a média de avaliação dos estudantes do Ensino Superior é maior que a dos estudantes do Supletivo, sendo que apenas os universitários estigmatizaram a variante não padrão.

Após esses primeiros resultados, Bortoni-Ricardo (2008) correlacionou o estudo da significação social da concordância verbal com a hipótese de que as formas menos estigmatizadas são as menos salientes, o que foi comprovado. A amostra para esse experimento foi expandida, contando com 360 universitários.

De acordo com a autora, a percepção da falta de concordância verbal como um estigma é direcionada pela ação da escola, o que indica que quanto mais escolarizado o falante, mais reações negativas emergem.

Quando relacionada a fatores linguísticos, a ausência de concordância verbal ocorrida em contextos mais frequentes, como conversas informais, por exemplo, é pouco estigmatizada, sendo que, para os pouco escolarizados, a não concordância verbal não é um traço saliente, estigmatizado.

Dessa forma, conclui-se que a pesquisa de Bortoni-Ricardo (2008, p. 375) procurou caracterizar dois grupos sociolinguísticos de Brasília considerando suas reações subjetivas à ausência de marcas flexionais no verbo. Além disso, o estudo mostrou que a camada menos escolarizada não tem atitude negativa frente à variação na concordância verbal, o 
que demonstra, segundo a autora, que não está implementada a "correção de cima", a qual assinala um avançado estágio no desenvolvimento de um traço linguístico.

\subsection{MIRANDA (2014)}

A pesquisa de Miranda (2014) foi realizada com falantes do Maranhão de duas cidades, Caxias (corpus do projeto Atitudes Linguísticas dos Falantes do Maranhão (ALFMA)) e São Luís (corpus da amostra Ludovicense), buscando focalizar crenças e atitudes dos maranhenses sobre a variação na concordância verbal com a segunda pessoa do singular (tu), além de realizar um estudo variacionista do tema. A amostra caxiense é composta por 90 falantes e a ludovicense por 96 , sendo estratificadas a partir do sexo, da faixa etária e da escolarização dos participantes da pesquisa.

A variável dependente da pesquisa é a presença/ausência de plural no verbo com o pronome sujeito tu (Tu conbeces lá o IFMA, o campus de Caxias?/ Tu pode ir só. ${ }^{4}$ e as variáveis consideradas são: proximidade do sujeito/verbo; paralelismo discursivo; tipo de sentença; forma de apresentação do verbo tempo verbal; saliência fônica; número de sílaba do verbo; frequência dos verbos; faixa etária; escolarização; sexo e localidade/etnia. A seguir, são apresentadas as variáveis consideradas relevantes pelo programa Goldvarb $\mathrm{X}^{5}$ e discutidos os achados a respeito das crenças e atitudes linguísticas dos falantes.

Os resultados gerais mostram que a aplicação da regra de concordância verbal padrão com a segunda pessoa do singular é muito baixa, tendo frequência 5,1\% na amostra de São Luís e 4,5\% na de Caxias. Mesmo com esses resultados, Miranda (2014) argumenta que não é possível assegurar que haja fortes indícios de mudança linguística, afirmando a necessidade de ser realizado um estudo em tempo real.

A respeito das variáveis selecionadas pelo Goldvarb X, para a amostra ludovicense, foram relevantes: saliência fônica, tempo verbal, número de sílaba do verbo, escolarização e frequência do verbo. Para a amostra caxiense, o programa selecionou as variáveis tipo de sentença, número de sílaba do verbo, escolarização e frequência do verbo. Como é possível notar, para as duas amostras a escolarização foi considerada relevante, entretanto, é preciso destacar que dos fatores controlados (ensino fundamental maior, ensino fundamental menor, sem escolarização, ensino médio e ensino superior) apenas os dois últimos foram mantidos nas duas amostras, pois nos outros não houve dados. Percebe-se no resultado de São Luís que falantes do Ensino Médio e do Ensino Superior usam a variante padrão da concordância verbal com o pronome tu de forma muito semelhante, como mostram os respectivos pesos relativos: .49 e .50 . Na amostra caxiense, por outro lado, houve uma sobressalência inesperada dos falantes do Ensino Médio sobre os do Ensino Superior: .59 e .41 , respectivamente.

A respeito das crenças e atitudes dos falantes maranhenses, salienta-se que foram correlacionadas com as variáveis sociais sexo, faixa etária e escolarização. Quando os participantes da pesquisa foram perguntados "Você acredita que o maranhense fala o

\footnotetext{
${ }^{4}$ Dados retirados de Miranda (2014, p. 81-82).

${ }^{5}$ Com o intuito de cumprir de forma objetiva a ideia de abordar a significação social da concordância verbal, apenas são elencadas as variáveis selecionadas, de modo que, para uma discussão profunda dos resultados quantitativos da pesquisa de Miranda (2014), a leitura de sua tese é indispensável.
} 
melhor português?” (MIRANDA, 2014, p. 120), a resposta, em geral, foi positiva, indicando que as crenças e as atitudes estão direcionadas pelo mito de que, no Maranhão, fala-se melhor o português.

Quando os entrevistados foram perguntados sobre a variação na concordância verbal (qual sentença é a melhor: você quer, tu queres, tu quer?), avaliaram positivamente a forma "você quer" em detrimento de "tu queres" e "tu quer", considerando as variáveis faixa etária e sexo. Na variável escolaridade, os participantes mais escolarizados avaliaram melhor a forma "tu queres", enquanto os falantes dos outros níveis, a forma "você quer". Enfatiza-se, nesse sentido, que os mais escolarizados se apegaram ao uso padrão da concordância verbal a partir do sistema pronominal consagrado (eu, tu, ele), enquanto os outros reagiram mais positivamente à forma "você quer", também não estigmatizada, desconstruindo o sistema pronominal padrão.

No que tange à pergunta "qual das três sentenças você usa mais: você quer, tu queres, tu quer?”, percebeu-se que a faixa etária não é importante. A variável escolarização, por outro lado, mostrou que os não escolarizados e os falantes do Ensino Fundamental preferem a forma "tu quer", enquanto os falantes do Ensino Médio e do Ensino Superior valorizam a forma "você quer". Quanto à variável sexo, percebeu-se que tanto homens quanto mulheres reconhecem as formas padrão, mas também não estigmatizam a não padrão.

Em síntese, Miranda (2014) assegura que o mito de que o maranhense fala o melhor português foi ratificado na pesquisa, pois está no imaginário da comunidade investigada e em boa parte do Estado, além de ser uma percepção de muitos brasileiros.

\subsection{OUSHIRO (2015)}

A pesquisa de Oushiro (2015) teve como objetivo analisar as identidades sociais por meio de usos linguísticos e qual a influência desses usos no processo de variação e mudança. Para isso, foi organizada uma robusta amostra do português paulistano, com 118 entrevistas sociolinguísticas, estratificadas a partir do sexo, da faixa etária, da escolaridade e da região de residência dos falantes e divididas, cada uma, em duas partes. $\mathrm{Na}$ primeira, os entrevistados falaram sobre a família, o bairro, a ocupação, entre outros temas, e, na segunda, expuseram suas avaliações ${ }^{7}$ sobre os temas investigados por Oushiro (2015), os quais são apresentados a seguir: realização do /e/ nasal como monotongo ou ditongo; pronúncia do /r/ em coda silábica como tepe ou retroflexo; concordância nominal de número; e concordância verbal de primeira e terceira pessoa do plural ${ }^{8}$.

A seguir, são apresentados, brevemente, os resultados encontrados para a primeira e a terceira pessoas do plural ${ }^{9}$. Em seguida, expõe-se o status da concordância verbal não

${ }^{6}$ Miranda (2014), como se nota, além de investigar a concordância verbal com a segunda pessoa do singular (tu), também percebeu que o uso de "você" é mais generalizado, pois nas frases expostas aos falantes, o pesquisador colocou como opção a forma "você quer" e constatou uma avaliação positiva para esta.

${ }^{7}$ Ressalta-se que não foram feitas perguntas para que os falantes avaliassem a concordância verbal.

${ }^{8}$ Nesta seção, são apresentados apenas os resultados a respeito da concordância verbal.

9 A leitura de Oushiro (2015) é bastante válida para que se tenha acesso detalhado aos resultados encontrados. 
padrão em P4 (primeira pessoa do plural) e P6 (terceira pessoa do plural). As variáveis linguísticas consideradas para o estudo da concordância verbal foram: saliência fônica, paralelismo discursivo, tipo de sujeito e posição de sujeito. Foi acrescentada à análise de P6 a variável animacidade do sujeito. Quanto às variáveis sociais, a autora considerou faixa etária, região de residência, origem dos pais, mobilidade, classe social e escolaridade.

Os resultados gerais mostram que, dos 1.150 dados de P4 e 10.224 dados de P6, houve variação apenas no estilo "conversação", sendo categórico o uso de CV padrão nos estilos leitura de "depoimento" e leitura de "notícia de jornal". Dos 1.074 dados de conversação (P4) e 9.480 (P6), a frequência de não marcação de plural é, respectivamente, de $9,4 \%$ e 12,6\%. Segundo a pesquisadora, as análises de P4 e P6 foram feitas separadamente, mas as variáveis selecionadas pelo programa são as mesmas, inclusive, a ordem de seleção, sendo a saliência fônica o fator mais importante, mostrando que formas verbais menos salientes desfavorecem a variante padrão da concordância verbal, tanto com P4 quanto com P6. As outras variáveis selecionadas foram: paralelismo discursivo, somente para P6, manifestando que sintagmas verbais com concordância favorecem a presença de outros sintagmas verbais com concordância; posição do sujeito, indicando que sujeitos imediatamente antepostos condicionam o uso padrão da concordância verbal; animacidade do sujeito (controlada somente com os dados de P6), sugerindo que sujeitos [+ humanos] desfavorecem a variante não padrão; tipo de sujeito, apresentando resultados semelhantes para P4 e P6, sendo que sujeitos pronominais condicionam a aplicação da regra de concordância verbal.

Com relação às variáveis sociais, só foram selecionadas como relevantes classe social e sexo. Com a primeira, vê-se que quanto mais baixa é a classe social do falante, mais é o emprego de marca zero na concordância. No que tange à segunda, percebe-se que os homens desfavorecem a variante padrão. Sobre a escolaridade, variável não selecionada, a autora comenta que há maior tendência à marca zero quanto menor for o grau de escolarização do informante e conclui afirmando que as variáveis sociais e linguísticas que condicionam a concordância verbal com P4 e P6 são, basicamente, as mesmas e possuem a mesma ordem de importância.

Após esse apanhado, Oushiro (2015), numa análise conjunta dos dados de P4 e P6, apresenta o status da concordância verbal não padrão. De acordo com a pesquisadora, os falantes menos escolarizados, de classe social e econômica mais baixas e que são mais enraizados em seus bairros, tendem a usar a concordância verbal não padrão mais significativamente com $\mathrm{P} 4$ do que com P6, o que não é observado em outros grupos de falantes. Compreende-se, assim, o estigma mais reforçado em torno da variante não padrão de $\mathrm{P} 4$ em detrimento da de $\mathrm{P} 6$, pois o grupo que favorece o uso não padrão de P4 é o mesmo que tem maior probabilidade de ser estigmatizado na/pela sociedade.

Ratificando essa ideia, a pesquisadora argumenta que pessoas cujas falas se associam a "padrões gramaticais" tendem a evitar veementemente o emprego de formas mais salientes, o grau 2 de P4, o que deve contribuir para a explicação de um maior estigma em torno da variante não padrão da primeira pessoa do plural em relação à forma não padrão de P6. A autora afirma que "[...] a estigmatização de certas variantes linguísticas advém do fato de que certos grupos com menor prestígio social tendem a empregá-las [...]" 
(OUSHIRO, 2015, p. 193), o que contribui para a ideia de que a forma linguística é estigmatizada porque o grupo que a usa também o é e não o contrário.

Diante dessa avaliação, Oushiro (2015) salienta que essa percepção tão sutil (que separa uso não padrão com P4 e uso não padrão com P6) não é, certamente, consciente. No entanto, a regularidade nos padrões de variação com P4 e P6 induz que falantes de uma determinada comunidade, em convívio com outros membros da mesma comunidade, são capazes de aprender regras muito complexas.

Em resumo, Oushiro (2015) concluiu que há uma distribuição semelhante entre P4 e P6, atendendo a um mesmo conjunto de regras variáveis, mas se diferenciando quanto ao valor social pelo fato de a variante não padrão de $\mathrm{P} 4$ ser favorecida em relação à de P6 por falantes menos escolarizados, de classe mais baixa e de mobilidade menor, os quais têm maior possibilidade de ser estigmatizados. Nos outros grupos, P4 e P6 não se diferenciam quanto às tendências de uso.

\section{AVALIAÇÃO SOCIAL E CRENÇAS LINGUÍSTICAS: COMO OS ESTUDANTES COMPREENDEM A VARIAÇÃO NA CONCORDÂNCIA VERBAL?}

Para a análise das crenças dos participantes desta pesquisa, foram realizados dois procedimentos metodológicos. O primeiro refere-se a perguntas realizadas no final da entrevista sociolinguística, as quais possibilitaram que os participantes da pesquisa avaliassem a variação na concordância verbal. O segundo, por sua vez, diz respeito à aplicação de um teste de reações subjetivas. Adiante, são discutidas as respostas dos estudantes durante a entrevista a respeito da variação na concordância verbal.

\subsection{AVALIAÇÃO SOCIOLINGUÍSTICA DA VARIAÇÃO NA CONCORDÂNCIA VERBAL DURANTE A ENTREVISTA}

Como se sabe, uma comunidade de fala diz respeito a um grupo de falantes que compartilha atitudes sociais frente à língua (LABOV, 2008[1972], p. 287). Essas atitudes estão ligadas às crenças a respeito da língua, ou seja, são influenciadas por aquilo que os sujeitos de uma comunidade acreditam (MARINE; BARBOSA, 2017). Assim, pode-se dizer que, ao tratar de atitudes linguísticas, abordam-se, também, as crenças e as identidades, pois as reações a determinadas variantes linguísticas pautam-se no saber social, histórico e cultural dos usuários de uma língua. Sabendo disso, são apresentadas as crenças linguísticas quanto à concordância verbal, verificadas por meio de perguntas realizadas aos estudantes no final da entrevista sociolinguística. A seguir, veem-se as perguntas:

Quadro 1: Questões realizadas no final da entrevista sociolinguística

1) Você acha que existe uma única forma de falar certo?

2) Qual dessas frases é a certa: a) "Os ladrão tinha” ou b) "Os ladrões tinham"?

3) Quem você acha que fala assim: "Os ladrão tinha"? 
4) Quem você acha que fala assim: “Os ladrões tinham”?

5) Como você diria essa frase: "Os ladrão tinha"? ou "Os ladrões tinham”? Fonte: Sousa (2019, p. 138).

Quanto à questão de número 1, salienta-se que não houve unanimidade nas respostas. O grupo da zona urbana ${ }^{10}$ destacou que existe uma única forma de falar certo, sendo que dois estudantes afirmaram que ninguém fala certo porque todo mundo erra. $\mathrm{O}$ que estaria sendo chamado de erro por esses alunos?

Se o erro tratado pelos estudantes ${ }^{11}$ da área urbana for o mesmo erro abordado pelas escolas, de modo geral, nota-se que esse pensamento dos alunos é bem acertada, visto que todos os falantes de uma língua, se julgados a partir da norma padrão, destoam das regras prescritas nos compêndios gramaticais. A crença linguística dos estudantes parece indicar uma reprodução do discurso escolar frente às variações, isto é, que determinadas formas linguísticas são erros e não devem, portanto, ser utilizadas.

Ao contrário dos estudantes da zona urbana, os da zona rural (três dos quatro entrevistados) acreditam que não existe uma única forma de falar certo. Eles se posicionaram de maneira crítica frente ao tema e destacaram questões importantes que implicam a forma de falar das pessoas. Dois estudantes elucidaram que o "lugar" influencia na forma de falar certo, sendo que um usou também a palavra sotaque. Notase que esses estudantes possuem conhecimentos sobre a variabilidade do português, sobretudo, quanto à variação diatópica ${ }^{12}$.

Quando foi feita a primeira pergunta para a participante 5, ela destacou que não existe uma única forma de falar certo "porque as pessoas pensam diferente" (P5RF), uma explicação pertinente para a variabilidade do português, isto é, se as pessoas pensam e são diferentes, como haverá uma única forma de falar? A participante 6 , por sua vez, pontuou que: "assim porque, não sei explicá, sabe, porque acho que tem alguns lugares que algumas pessoas acha que é certo e tem muitos lugares que são, que também falam outra coisa, mas que também são certo" (P6RF). Esta estudante reconhece, implicitamente, que existe variação linguística, pois afirma que de um lugar para outro há diferentes maneiras de falar a mesma coisa, reconhecendo, assim, a variação diatópica.

O participante 7 também assinala que o lugar é importante para falar certo. Ele relata o seguinte:

[...] eu acho assim... que uma forma de falá certo... porque cada lugá tem assim um sotaque, né, diferente, só que uma forma de falá certo não é assim, bem assim, porque quando a

\footnotetext{
${ }^{10}$ Apenas três estudantes responderam a esta questão dos quatro entrevistados desse grupo.

11 Os participantes da pesquisa são identificados da seguinte forma: "P" significa participante; o número representa a caracterização do participante (de 1 a 4 participantes da zona urbana e de 5 a 8, da zona rural); "R" significa rural e "U" urbano; "F" significa sexo feminino e " $M$ ", sexo masculino.

${ }^{12}$ A variação diatópica talvez seja a mais reconhecida pelo grande público brasileiro, haja vista a dimensão territorial do Brasil. Pode-se atribuir este reconhecimento também ao fluxo migratório do campo para a cidade, já que quando pessoas deixam o campo, deixam também parte de sua família e, ao passarem períodos fora do seu lugar de origem, adquirem marcas linguísticas que caracterizam seu novo espaço de moradia, o que faz com que as pessoas que ficaram no campo, ao manterem contato com as que foram para a cidade, percebam que sua fala, de alguma maneira, está diferente.
} 
pessoa nasce, ela não vai falando, vai desenvolvendo [...] ninguém nasce sabendo, então você vai crescendo... acho que pra falá certo, pra ser uma pessoa, assim, formada mesmo, acho que você tem que entrá na escola, porque assim você vai falá melhor. (P7RM).

A partir desse fragmento, é possível depreender que, para este estudante, o falar certo está ligado ao lugar, porque cada lugar tem um sotaque, mas também está ligado à escola. Salienta-se que este estudante foi o único a utilizar a palavra "sotaque", talvez por que mora com a avó na zona rural de Tucano-BA, enquanto a mãe trabalha em São Paulo, o que pode justificar o uso de tal palavra, uma vez que, entre a família, deve haver comentários sobre o possível sotaque diferenciado da mãe do estudante ${ }^{13}$.

Além disso, é válido comentar que, na fala do participante 7 , é evidente que, para ele, existe um "falar melhor" e um "falar pior", sendo o primeiro possibilitado pela escola, já que é o espaço em que se ensina a norma padrão. A crença linguística desse estudante evidencia que ainda é muito forte a dicotomia "certo" e "errado" pregada pela escola até os dias atuais, o que pode levar a uma atitude linguística de preconceito, já que se acredita que uma forma é melhor que a outra.

Uma pesquisa que reforça esse entendimento é a de Barbosa e Cuba (2015, p. 81), a qual constatou que "[...] os alunos (e, consequentemente, os professores) ainda pensam que existem maneiras erradas de falar e que a única maneira correta é a que está na gramática". Os resultados obtidos quanto à crença linguística de que existe uma única forma de falar certo também foram constatados por Cyranka (2007).

No que tange à questão de número 2 (Qual dessas frases é a certa: a) "Os ladrão tinha" ou b) "Os ladrões tinham"?), os estudantes não justificaram, de modo geral, suas respostas, apenas uma da zona rural, a participante 6 , a qual disse que a frase certa era a da letra $b$, enfatizando que: "é porque cê falou, né, que os la... eu acho que são dois, né, são dois?" (P6RF). Percebe-se que a estudante reconhece a regra padrão da concordância verbal, de modo que fica claro que ela opta pela letra $b$ como a correta porque compreende que se o sujeito está no plural, o verbo também deve estar. Ressalta-se que dos oito participantes, sete reconheceram a variante padrão da concordância verbal, sendo que para os estudantes do campo e da cidade, grosso modo, a ausência das marcas de plural é avaliada como errada.

Quando perguntados sobre quem falaria as frases com marcas de plural ou sem as marcas (questões 3 - Quem você acha que fala assim: "Os ladrão tinha"? e 4 - Quem você acha que fala assim: "Os ladrões tinham”?), os participantes atribuíram a variante padrão (os ladrões tinham), em geral, a uma profissão de alto status social, o que indica que os estudantes reconhecem que o "falar certo" está relacionado, também, à classe social. Essa avaliação realizada pelos alunos é interessante por mostrar que, mesmo sendo estudantes do Ensino Fundamental, notam que a língua é falada de forma diferente a depender do lugar e da profissão, como é apontado pelos alunos da zona rural, os quais sugerem que essas duas variáveis são importantes para a forma de falar.

${ }^{13}$ Este estudante mora com a avó na zona rural de Tucano-BA desde quando nasceu e foi este que viajou, no final do ano de 2017, para São Paulo, passando a residir com a mãe. 
Quanto à variante não padrão (os ladrão tinha), os alunos transpareceram a crença de que quem fala de tal forma são as pessoas menos escolarizadas. Cinco estudantes disseram que quem falaria a variante não padrão seria um profissional de pouco reconhecimento social, dois alunos não responderam e um disse que quem falaria de tal forma seria alguém que estudou.

Referente à última questão, a de número 5 (Como você diria essa frase: "Os ladrão tinha"? ou "Os ladrões tinham"?), notou-se uma diferença quanto à crença de usar a variante não padrão da concordância verbal. Três dos quatro entrevistados da zona urbana disseram que usariam a forma não padrão, enquanto todos os estudantes da zona rural disseram que usariam a forma padrão, o que se mostra uma informação pertinente pelo significado social atribuído por esse grupo à norma padrão.

Os estudantes da cidade, mesmo reconhecendo a forma padrão, afirmam usar a não padrão, o que talvez possa ser explicado pelo menor monitoramento desse grupo durante a entrevista e também pelo fato de, em sua avaliação, a forma não padrão não chegar a ser um estereótipo, mas um marcador, nos termos de Labov (2008 [1972]). A respeito dessa questão de não estigmatização da variante não padrão, Santos (1996, p. 108) afirma:

Já antes de ingressar na escola o aluno é advertido, em maior ou menor grau, de que há objetos linguísticos absolutamente "certos" e objetos absolutamente "errados". A escola desenvolve e dá "legitimidade" a essas crenças que, em certos casos, estavam apenas embrionárias. Não obstante, na presença de uma dada variante e mesmo demonstrando predisposição para aceitar as crenças escolares relativas a esse caso particular, o educando pode não mostrar atitude coerente, não estigmatizando o valor que a escola quer proscrever. (SANTOS, 1996, p. 108).

É importante destacar que avaliar e usar são ações diferentes, visto que é possível avaliar como errada uma determinada forma, como foi feito pelos estudantes da zona urbana na questão 2, mas usá-la, que é o que mostram as respostas para esta última questão. Isso é perceptível, também, na fala do participante 7, que diz: "se fosse, assim, falá, assim, que foi dois ladrão ou mais, eu ia falá: quando eu entrei em casa, os ladrões tinham levado minha televisão" (P7RM). Percebe-se que, na justificativa, o estudante não marca o plural: "foi dois ladrão", mas quando vai avaliar as frases como certas ou erradas, o plural é marcado tanto no sintagma nominal quanto no sintagma verbal, o que ratifica a interpretação de que uso e avaliação são ações distintas.

Realizada essa primeira análise das crenças dos estudantes, pode-se concluir que o grupo de alunos da zona rural, em geral, detém uma avaliação sociolinguística mais acentuada quanto à variação, quando reconhece, por exemplo, que existe mais de uma forma de falar corretamente. Este grupo considera que existem fatores que influenciam a maneira de falar das pessoas, como a escola e o lugar, o que reforça uma visão, mesmo que desproposital, da Sociolinguística.

Como já foi apresentado, os dois grupos de estudantes reconhecem como "certa" a variante em que há marcas de plural tanto no sintagma nominal sujeito quanto no sintagma verbal, assim como os estudantes investigados por Bortoni-Ricardo (2008). Por outro lado, os alunos da zona urbana mostram que sua avaliação não estabelece relação direta com seu uso, pois afirmam usar a variante não padrão da concordância verbal, 
enquanto os da zona rural argumentam em favor do uso padrão da concordância, fato que demonstra que os estudantes da área rural se monitoraram mais e, por isso, avaliam a concordância verbal como um estereótipo linguístico, como é possível constatar nas próximas seções, em que são apresentados os resultados do teste de reações subjetivas.

É interessante pontuar que, mesmo reconhecendo a variabilidade do português, os estudantes do campo não têm a crença de que construções linguísticas do tipo "os ladrão tinha" são, também, variação, o que se explica pelo fato de, na escola e nos livros didáticos, haver uma valorização maior dos três tipos básicos de variação: social, geográfica e estilística, sem que as variações morfossintáticas, na maioria das vezes, sejam discutidas. Dessa forma, os alunos creem que a variação na concordância verbal é, simplesmente, "erro linguístico".

\subsection{O QUE O TESTE DE REAÇÕES SUBJETIVAS MOSTROU?}

Os estudos das crenças e das atitudes estão fortemente ligados, em território nacional, aos professores de línguas, aos estudantes e ao ensino-aprendizagem de modo geral, estando esta pesquisa neste âmbito, já que se ocupa das reações subjetivas de estudantes frente à variação na concordância verbal.

O teste aplicado teve como base o que foi criado por Barbosa e Cuba (2015), resultando num teste que possibilita depreender as reações subjetivas ou crenças dos estudantes frente ao fenômeno da variação na concordância verbal. São apresentadas, a seguir, as crenças linguísticas dos estudantes.

\subsubsection{As reações subjetivas dos estudantes investigados}

Os resultados obtidos pela aplicação dos testes, grosso modo, confirmam as crenças frente à variação na concordância verbal, reafirmando o que foi notado nas respostas dos estudantes às questões realizadas no final da entrevista sociolinguística. A seguir, vê-se um quadro em que se faz uma comparação entre os estudantes da cidade e do campo, considerando não só as respostas às questões colocadas na seção anterior, mas a entrevista sociolinguística como um todo.

Quadro 2: Os estudantes do campo e da cidade: uma comparação necessária

\begin{tabular}{|c|c|}
\hline ESTUDANTES DO CAMPO & ESTUDANTES DA CIDADE \\
\hline $\begin{array}{c}\text { Reconhecimento da variante padrão da } \\
\text { concordância verbal. }\end{array}$ & $\begin{array}{c}\text { Reconhecimento da variante padrão } \\
\text { da concordância verbal. }\end{array}$ \\
\hline $\begin{array}{c}\text { Afirmam não usar a variante não } \\
\text { padrão. }\end{array}$ & Afirmam usar a variante não padrão. \\
\hline $\begin{array}{c}\text { A variação na concordância verbal é } \\
\text { um estereótipo linguístico, uma regra } \\
\text { descontínua. }\end{array}$ & $\begin{array}{c}\text { A variação na concordância verbal é } \\
\text { um marcador linguístico, uma regra gradual. }\end{array}$ \\
\hline
\end{tabular}

Fonte: Adaptado de Sousa (2019, p. 142). 
Como é possível perceber no quadro, os estudantes do campo assumiram um comportamento linguístico distinto dos estudantes da cidade a respeito da variação na concordância verbal, mostrando-se estudantes mais reflexivos e críticos. Uma possível justificativa para esse fato é achar que o domínio do português padrão possibilita ascensão social, além do inconsciente desejo de se "urbanizarem", ou, ainda, uma reação de medo de serem julgados.

Aventa-se, também, o ensino de língua portuguesa na escola do campo como justificativa, pois, como foi visto, respeita a variação à medida que ensina a norma padrão. Esse fator, de alguma forma, contribui para que os alunos da zona rural mostrem conhecimentos metalinguísticos. Além disso, a escola enquanto espaço em que se aprendem os conhecimentos "oficiais" parece ser mais valorizada pelos estudantes do campo do que pelos da cidade, um fato que pode explicar as crenças desse grupo em torno da variação na concordância verbal, que é vista como um estigma porque, segundo Bortoni-Ricardo (2008), é direcionada pela escola para que seja percebida dessa forma.

Passando à discussão das crenças linguísticas dos estudantes, algumas questões já podem ser expostas. Abaixo, seguem algumas crenças dos estudantes (rural e urbano) apreendidas no teste aplicado.

1. Os estudantes falam e escrevem bem.

2. Os adultos falam melhor que os jovens.

3. Para escrever direito é necessário melhorar o jeito de falar.

4. Um bom professor de português é aquele que fala de acordo com as regras da gramática.

5. O jeito de falar é igual ao de quem convive no lugar onde mora ${ }^{14}$.

6. Orgulho do jeito de falar.

Essas crenças mostram que os falantes investigados estão presos a falsas certezas enraizadas na sociedade. Com exceção da crença de número 1, as manifestações dos estudantes não foram surpreendentes, mas esperadas, visto que, de certa forma, integram o imaginário dos falantes de português.

A crença expressa pelos estudantes de que falam e escrevem bem foi inesperada porque, quase sempre, os falantes "comuns" de português defendem a ideia de que não sabem a língua, fazendo uma confusão entre o que é língua e o que é gramática. Para a maioria dos falantes, saber uma língua é seguir as regras gramaticais prescritas nos compêndios escolares, uma crença equivocada, pois, como afirma Bagno (2000, p. 9-10) "A língua é um enorme iceberg flutuando no mar do tempo, e a gramática normativa é a tentativa de descrever apenas uma parcela mais visível dele, a chamada norma culta." Essa crença dos estudantes não coaduna com a crença dos educandos pesquisados por Cyranka (2007, p. 123), os quais, “[...] em geral, não consideram que falam nem que escrevem bem. E mais, condicionam o desenvolvimento dessa competência a falsos instrumentos, como

${ }^{14}$ Essa crença reforça o "mito do não sotaque", percebido também por Aguilera (2008a). 
aprender regras de gramática ou de ortografia.”, revelando, assim, a falsa ideia de que saber regra gramatical e ortografia garante uma escrita e fala coerentes ${ }^{15}$.

As outras crenças $(2,3$ e 4$)$ apresentadas anteriormente evidenciam que tanto os estudantes do campo quanto os da cidade alimentam falsas ideias em torno da língua, pois acreditam que adultos falam melhor que jovens (crença 2); acreditam na relação direta entre fala e escrita (crença 3) e na construção social de que um professor de português é aquele que segue a norma padrão (crença 4). Essas crenças podem ser ressignificadas, afinal, crenças são mutáveis. Para essa ressignificação, acredita-se que sejam necessárias reflexões em sala de aula que ultrapassem o ensino-aprendizagem da norma padrão, de modo a permitir que professores e, por meio deles, alunos reconheçam que o estudo da língua deve ocorrer não a partir da dicotomia "certo" e "errado", mas a partir de competências mais amplas, como o estudo do texto em vários gêneros formais e informais, evidenciando que a informalidade também é possível na escrita, assim como a formalidade é possível na fala; mostrando que é necessário adequar a língua aos contextos comunicativos, havendo a possibilidade de um professor de língua, por exemplo, assim como todas as pessoas, independentemente do grau de escolarização, da profissão, do sexo e da idade, usarem variantes não padrão em determinados momentos, o que não diminui ou inferioriza essas pessoas, até por que essas variantes não são menores, ainda que, muitas vezes, pense-se assim.

As crenças 5 e 6 mostram que os estudantes têm orgulho de sua maneira de falar, assim como não creem que falam diferente das pessoas de suas respectivas comunidades, o que leva a pensar que os estudantes, em geral, orgulham-se de sua identidade linguística: no caso dos estudantes do campo, uma identidade rural; no caso dos estudantes da cidade, urbana. Ressalta-se, no entanto, que uma estudante da zona rural não tem a crença de que usa a língua da mesma forma que as pessoas com quem convive no lugar onde mora. Para ela, sua fala é diferente porque as pessoas "[...] não respeitam as regras gramaticais, principalmente plural e singular.” (P5RF). Com esta afirmação, nota-se a percepção linguística desta estudante, no que tange, sobretudo, à concordância, já que ela se refere ao número plural/singular.

Os resultados de outras pesquisas evidenciam, como a de Barbosa e Cuba (2015), por exemplo, as quais investigaram crenças e atitudes linguísticas de alunos do Ensino Médio em escolas públicas de Uberaba, que:

1. os alunos [...] têm orgulho de seu modo de falar [...];

2. acreditam que a língua escrita é mais correta que a falada, e que portanto escrevem melhor do que falam;

$[\ldots]$

4. pensam que os adultos falam melhor que os jovens;

$[\ldots]$

7. demonstram que um professor de Português competente deve falar de acordo com as regras da gramática; [...] (BARBOSA; CUBA, 2015, p. 80-81).

${ }^{15}$ Se a amostra desta pesquisa fosse maior, talvez a realidade fosse diferente. É uma tarefa para trabalhos futuros: a expansão da amostra. 
Das crenças apresentadas na citação, nota-se que apenas a de número 2 não ratifica as apresentadas nesta pesquisa, pois os estudantes aqui investigados, como já foi explicitado, não creem que falam e escrevem mal. Inclusive, é de bom senso refutar essa ideia de que existem formas de falar e escrever que são ruins. Tanto a fala quanto escrita podem apresentar fracos argumentos, incoerências, mas do ponto de vista da variação linguística, um texto oral ou escrito não é considerado inferior ou ruim por nele constarem fenômenos variáveis. É claro que outras questões do ponto de vista da produção e organização textual podem ser consideradas para que um texto seja refinado, como função comunicativa, domínio lexical e uso restrito de conectivos, como foi apontado por Ferminio (2017), por exemplo.

Voltando à discussão sobre as crenças, argumenta-se, ainda, a respeito da crença de número 2 da citação, que as respostas à primeira questão do teste de crenças aplicado aos participantes desta pesquisa, que é: "Para você, a língua escrita é mais certa do que a língua falada?”, não tem uma resposta fechada, visto que os estudantes não chegaram a um consenso, ou seja, enquanto os da zona rural creem que a língua escrita é mais correta que a falada, o que pode ser justificado pela falsa ideia de que a escrita é sempre formal, os estudantes da zona urbana acreditam que a escrita não é mais certa que a fala.

Acredita-se que essa crença (a escrita é mais certa que a fala) pode ser explicada por outras veiculadas no ambiente escolar: "escreva direito, não como fala"; "escrever é difícil, por isso nem todo mundo escreve, embora fale", por exemplo. Como os alunos da zona rural parecem valorizar mais a escola como lugar onde se "aprende", talvez por isso tenham supervalorizado a escrita em detrimento da fala, coadunando com o resultado de Cyranka (2007) e Barbosa e Cuba (2015).

No que tange às crenças sobre a variação na concordância verbal, três perguntas foram colocadas para os estudantes: “A frase 'nós é bonito' está certa?”, “A frase 'eles quer comida' está certa?” e “Que profissão você acha que exerce a pessoa que fala assim: 'nós é bonito' e 'eles quer comida'?” As respostas a essas questões revelaram que a variação na concordância verbal não tem o mesmo valor para os dois grupos de estudantes pesquisados.

De acordo com Bortoni-Ricardo (2008), o grau de escolarização das pessoas parece condicionar o valor que elas atribuem às variantes não padrão. Neste artigo, como não foi feita uma análise considerando a variável escolarização, não é possível ratificar o que a autora percebeu em seu estudo. Por outro lado, argumenta-se que a visão dos estudantes do campo sobre a escola, a língua, assim como mais "monitoramento" podem ser caminhos para explicar suas crenças, em detrimento dos da cidade.

Os educandos da zona rural mostraram, em suas respostas ao teste, que tanto reconhecem a variante padrão da concordância verbal como julgam como erradas as formas "nós é" e "eles quer", comprovando suas respostas anteriores, no final da entrevista. Além disso, esse mesmo grupo afirma que a escolarização é importante para que as pessoas sigam a norma padrão, atribuindo a variante não padrão a quem estudou pouco.

Os alunos da zona urbana, por outro lado, acreditam que a frase "nós é" está certa; dividem-se quanto à frase "eles quer", assim como em relação à escolarização das pessoas que usam a variante não padrão. Esse fato reforça que, quando as variantes padrão e não 
padrão são apresentadas para serem julgadas juntas (como foi feito nas questões ao final da entrevista), os alunos reconhecem a forma padrão. Entretanto, se apresentada somente a forma não padrão, por reconhecerem que a usam, os alunos julgam-na como certa ou não chegam a um consenso, no caso de P6, por exemplo. Esse fato indica que esses estudantes têm dificuldade em reconhecer o valor social das variantes não padrão.

As crenças sobre a variação na concordância verbal parecem indicar o que foi pontuado por Oushiro (2015), a qual afirmou que, quanto à distribuição de P4 e P6, notase que atende a um mesmo conjunto de regras variáveis, mas com relação ao valor social, a variante não padrão de P4 mostra-se mais estigmatizada. Os estudantes investigados nesta pesquisa, principalmente os da cidade, dão indícios de que reconhecem esse fato, já que julgaram como errada a forma não padrão de P4, mas não chegaram a um consenso, nesse momento, a respeito da variante não padrão de $\mathrm{P} 6$, o que não ocorreu com os estudantes do campo, os quais avaliaram como erradas as formas não padrão de P4 e P6.

Após colocar essas questões primeiras a respeito das crenças sobre o uso não padrão da concordância verbal, foram apresentadas duas situações aos estudantes para que opinassem sobre elas e avaliassem formas não padrão, cujos resultados são apresentados a seguir:

Inicialmente, mostrou-se para os alunos, individualmente, um texto em que o professor dizia: “Ai negada! Nóis vai estudá português assim!”. Depois que eles leram, foram feitas as seguintes perguntas:

Quadro 3: Questões do teste sobre a variação na primeira pessoa do plural (P4)

\begin{tabular}{|l|}
\hline a) Você acha que esse professor é um bom professor de português? Por quê? \\
\hline b) Por que você acha que os alunos estão espantados? \\
\hline c) Você fala nós vai? Se responder não, perguntar por quê. \\
\hline d) Onde você mora, é comum falar nós vai ou nós vamos? \\
\hline e) O que você acha de falar nós vai? \\
\hline f) Você acha que falar nós vai é típico da zona rural ou da zona urbana? Por quê? \\
\hline g) Você acha que falar nós vai tem a ver com o nível de estudo da pessoa? Por quê? \\
\hline h) Você acha que as pessoas que falam nós vai sofrem preconceito? Por quê? \\
\hline
\end{tabular}

Fonte: Adaptado de Sousa (2019, p. 148).

As respostas para essas questões foram gravadas. O mesmo procedimento foi realizado no segundo momento do teste: foi apresentado um outro texto, um diálogo entre mãe e filho, e foram realizadas perguntas semelhantes ao do primeiro momento. A seguir, apresentam-se o diálogo e as questões realizadas:

- Mãe, a senhora tem que ir na escola amanhã.

- O que ocê aprontô, Junin?

- Meus professô disseru qu'eu só falo errado.

- E eles quer que eu faça o quê

- Quer que a senhora me corrija!

Fonte: Sousa (2019, p. 149).

As perguntas realizadas foram: 
Quadro 4: Questões do teste sobre a variação na terceira pessoa do plural (P6)

\begin{tabular}{|l|}
\hline a) Você acha que tem como a mãe corrigir a fala do filho? Por quê? \\
b) Para você, o que seria falar errado e falar certo? Quem, em sua opinião, fala \\
errado e quem fala certo? \\
\hline c) Você fala eles quer? Se responder não, perguntar por quê. \\
\hline d) Onde você mora, é comum falar eles quer ou eles querem? \\
\hline e) O que você acha de falar eles quer? \\
f) Você acha que falar eles quer é típico da zona rural ou da zona urbana? Por \\
quê? \\
guê? Você acha que falar eles quer tem a ver com o nível de estudo da pessoa? Por \\
\hline h) Você acha que as pessoas que falam eles quer sofrem preconceito? Por quê?
\end{tabular}
Fonte: Sousa (2019, p. 149).

A respeito das questões a) e b) expostas no quadro 3, e a) e b) do quadro 4, ressaltase que, na primeira pergunta do quadro 12, os estudantes julgaram o professor de português como ruim, "pela forma de falá. As palavras estão erradas" (P5RF); "porque pelo jeito de falá, os alunos não vão entender" (P6RF); "porque ele falou errado" (P8RM); "por causa do jeito dele fala" (P3UM). Apenas uma estudante da zona urbana não julgou o professor como ruim. Todos os demais que responderam ao teste avaliaram o fato de o professor não seguir a norma padrão como algo negativo, expondo sua crença de que um professor de língua portuguesa deve usar a língua de acordo com as regras da gramática, ratificando o que responderam no teste de crenças.

Quanto à segunda questão do quadro 12, os estudantes justificaram que os alunos da classe estão espantados pelo modo de falar do professor, levantando questões não só puramente gramaticais, mas relacionadas à informalidade do docente em sala de aula ao usar termos como "negada". Esse fato mostra que os estudantes enxergam a figura do professor como aquele que, além de ter de seguir o padrão, deve usar uma linguagem mais formal na aula, o que é fruto, de modo geral, do pensamento ortodoxo de que o professor é o dono do saber, é quem sabe "tudo" e, por isso, deve se diferenciar dos estudantes, inclusive, pelo uso da linguagem, o qual denota poder.

Em relação à primeira questão do quadro 13, percebeu-se que os alunos acreditam que a mãe pode "corrigir" a fala do filho "se ela mudar a forma dela falá também, porque ele tá aprendendo pela forma que ela fala" (P5RF). Um dos estudantes, o P8RM, destacou que se o garoto estudar mais, vai mudar sua forma de falar, atribuindo à escola, como já foi feito em outro momento pelo P7RM, o papel de ensinar a norma culta, o que deve, de fato, ocorrer, mas sem que as outras variedades linguísticas sejam desrespeitadas.

O estudante P4UM corroborou o pensamento de P5RF, ao afirmar que "se ela [mãe] falá certo, ele [filho] também vai fazê certo". Os demais estudantes não diferenciam sua avaliação, demonstrando que se a mãe falar "certo", terá condições de corrigir o filho; caso contrário, não poderá corrigi-lo, porque ela mesma fala "errado". Esse posicionamento dos estudantes evidencia que integra seu imaginário a crença de "fala certa" e "fala errada". Mesmo apresentando conhecimentos metalinguísticos e 
reconhecendo a variação linguística, os estudantes do campo mostraram-se ainda presos a essa noção obsoleta perpetrada ao longo do tempo pelas gramáticas normativas e pelos livros didáticos, e reproduzida em sala de aula por um vasto número de professores. $\mathrm{O}$ trabalho dos docentes de Língua Portuguesa deve pautar-se, também, na desconstrução de mitos que rondam a língua insistentemente, repetidos tanto por estudiosos de uma gramática do português europeu quanto por leigos que foram forjados a acreditar que não sabem sua própria língua porque não conhecem regras gramaticais. A sala de aula deve, portanto, ser o espaço para o estudo da língua e não, somente, para o estudo da gramática; estudar a língua é, pois, reconhecer suas variedades e saber usá-las no momento adequado; trabalhar com textos orais e escritos, formais e informais; discutir os tipos e os gêneros textuais pautando-se na realidade sócio-cultural dos estudantes. Enfim, o ensino de Língua Portuguesa deve permitir que os estudantes sejam letrados e capazes de refletir sobre a língua a partir dos usos reais.

No que tange à segunda questão do quadro 4, em que os estudantes responderam sobre o que seria falar certo e falar errado, percebeu-se, quanto ao componente cognitivo, que o falar certo se relaciona a usar as palavras com todas as letras e falar errado seria omitir letras, ou seja, "problema" seria o certo, enquanto "poblema" o errado. Essa é uma visão ingênua dos estudantes; por outro lado, a aluna P5RF afirmou que:

Falar errado é violar as regras da situação, gramática, e falar certo é seguir as regras do português corretamente. Fala errado aquelas pessoas que têm um nível de escolaridade mais baixo, que não estudaram muito, e as pessoas que falam certo, aquelas acostumadas a estudar, ler. (Grifo nosso, P5RF).

Como é possível notar na citação, esta estudante da zona rural demonstra, mais uma vez, a crença de que o certo é seguir a gramática e o errado é violar suas regras. É interessante o que está em negrito porque a estudante atribui à baixa escolarização o "falar errado", demonstrando que conhece a função da escola e defende o uso padrão. Ratificando a ideia de que usar e avaliar, assim como usar e ter crenças sobre algo são aspectos distintos, nota-se que a estudante usa a variante não padrão da concordância verbal em "Fala errado aquelas pessoas", o que pode ser justificado pela posposição do sujeito. É importante ressaltar, ainda, que a aluna afirma que estudar e ler são ações que favorecem o uso da língua padrão. A citação é, em geral, importante pelo posicionamento da estudante frente ao uso da língua, pois ela reconhece que circunstâncias não linguísticas, como estudar, ler, nível de escolarização favorecem o uso da língua padrão, o que, como se sabe, é confirmado pelas pesquisas sociolinguísticas. Pode-se dizer que, de todos os participantes, esta, em especial, é a mais "antagônica", já que defende o uso padrão, mas, inconscientemente, reconhece fatores que influenciam a forma como as pessoas usam a língua.

Até aqui, foram apresentadas e discutidas quatro questões que dizem respeito às reações subjetivas dos estudantes de um modo bem geral, sem se relacionarem diretamente com a variação na concordância verbal, mas que são importantes para compreender os pensamentos dos estudantes sobre a língua. Agora, passa-se à discussão 
das questões que permitem analisar como os estudantes reagem à variante não padrão da concordância verbal.

Aos alunos, foram feitas as seguintes perguntas: "Você fala nós vai?" e "Você fala eles quer?". As respostas mostraram que os estudantes do campo creem que não usam a variante não padrão de P4 e P6, o que permite inferir que esses alunos, como vem sendo demonstrado ao longo dessa análise, percebem o valor negativo das formas não padrão. Por outro lado, os alunos da cidade admitiram usar a forma "nós vai". Acredita-se que esses estudantes podem ter relacionado "nós vai" com "a gente vai", ambas as construções com ideia de plural, por isso afirmaram usar a variante não padrão. Como nesta pesquisa não foi controlada a forma "a gente", não é possível fazer uma afirmação mais precisa. Além disso, atribui-se esse uso por parte dos alunos da cidade ao não reconhecimento do estigma social dessa variante. Quanto à P6, os educandos da zona urbana dividiram-se nas respostas, sendo que a P2UF teve dificuldade em reconhecer e diferenciar plural/singular.

Ainda sobre a questão c) dos quadros 3 e 4, é válido transcrever o que disseram os alunos quando se perguntou se falavam "nós vai": "Não. Ah, porque, além de tá errado, eu não suporto ouvir isso" (P5RF); "Não. Porque o certo é nós vamos." (P6RF); "Não, porque não..." (P7RM). Observa-se que os estudantes do campo, principalmente as meninas, além de reconhecerem a forma padrão, julgam a não padrão como errada. Ressalta-se o comentário da participante 6, a qual se mostra aversiva ao não padrão, afirmando que não suporta ouvir isso, referindo-se a "nós vai". Esta estudante reage assim à variante "não padrão" por julgar sua forma de falar melhor, inclusive, melhor que a das pessoas com quem convive no lugar onde mora. Como é visto adiante, ela atribui o fato de falar diferente ao acesso que tem à escola.

Os alunos da cidade não explicaram suas respostas, apenas afirmando que usam "nós vai". Quanto às respostas para P6, uma única estudante deste grupo afirmou não usar "eles quer", porque, segundo ela, "o certo é eles querem" (P1UF). Os demais estudantes, P3UM e P4UM, afirmaram usar a forma não padrão e, como exposto antes, a P2UF não reconheceu singular/plural, ora dizendo usar "eles quer", ora "eles querem".

Infere-se que essa posição de usar a forma não padrão da concordância verbal por parte do grupo de estudantes da cidade pode ser explicada por sua relação com a escola, que é diferente da relação dos alunos do campo. Embora outros fatores tenham sido verificados na busca por explicações para os resultados desta pesquisa, não foram encontradas diferenças entre os dois grupos investigados (campo e cidade) quanto ao fato de os estudantes terem ou não redes sociais, assistirem ou não à TV, ouvirem ou não o rádio e, inclusive, a respeito da escolaridade dos pais. Apenas um fator junto à relação estudante-escola pode contribuir para explicar os resultados, qual seja o hábito de leitura. Dos entrevistados, dois da cidade, P2UF e P4UM, afirmaram que não leem, o que se mostra um fato considerável, pois todos os outros asseveraram o hábito de leitura.

Referente às questões d) dos quadros 12 e 13: "Onde você mora, é comum falar nós vai ou nós vamos?" e "Onde você mora, é comum falar eles quer ou eles querem?”, esclarece-se que são apresentadas junto com as questões f) dos quadros: "Você acha que falar nós vai é típico da zona rural ou da zona urbana? Por quê?" e "Você acha 
que falar eles quer é típico da zona rural ou da zona urbana? Por quê?”, pois estas últimas relacionam-se e lançam luzes às respostas das primeiras, como é perceptível a seguir.

Os estudantes, nas questões d), mostraram-se divididos, afirmando, por um lado, que as pessoas do campo e da cidade usam a forma padrão e, por outro, a não padrão. $\mathrm{O}$ educando P4UM, por exemplo, destacou que "Alguns fala certo, outros fala meio errado.", dicotomizando os falantes. Destaca-se que ele mesmo, em sua resposta, apresenta variação na concordância verbal, o que reforça a ideia de que não percebe a variante não padrão.

Enquanto os estudantes do campo, em geral, afirmam que seus conterrâneos usam as variantes "Nós vamos" e "Eles querem" por reconhecerem o prestígio dessas formas linguísticas e o desprestígio das variantes não padrão, a aluna P5RF assegura que as pessoas da zona rural usam "Nós vai. A maioria das pessoas falam assim. Falam assim porque muitas pessoas não tiveram acesso à escola". Vê-se, então, que essa estudante, como dito anteriormente, crê que a escola é peça-chave para que as pessoas usem a norma padrão. Como a maioria delas não teve acesso ao ensino formal, fala "errado", como essa mesma participante disse em outros momentos do teste, já comentados aqui.

As questões d) são relacionadas com as f) porque, por incrível que pareça, há um fato curioso que contribui para o posicionamento dos estudantes do campo. Os alunos investigados nesta pesquisa atribuíram as variantes "nós vai" e "eles quer" à zona rural. Entretanto, os alunos do campo dividem o espaço rural entre aqueles que tiveram acesso à escola e os que não tiveram; entre os caipiras e os não caipiras; entre os novos e os velhos. Essa afirmação pode ser comprovada nas falas que seguem: é típico da zona rural “[...] porque na zona rural, eu acho que é um lugar onde mais tem pessoas que não tiveram muito acesso à escola, que estudaram menos.” (P5RF).

Além dessa fala, que mostra uma visão da zona rural como um espaço historicamente atrasado ${ }^{16}$, há outras que evidenciam a tentativa de os estudantes do campo se colocarem num grupo à parte dentro de sua comunidade, negando, dessa forma, sua identidade linguística rural por compreender o estigma das formas não padrão da concordância verbal, são elas: "Os caipira que fala assim, modo de falá do povo antigo" (P8RM); "Rural, porque no rural não frequenta muito a escola e também porque é da zona rural falá isso, falá caipirês" (P6RF). Pelas respostas, percebe-se que os estudantes se colocam num grupo estudado, não caipira e de jovens, comprovando a ideia de que a fala rural é "atrasada" e "errada" quando usada por pessoas do grupo não estudado, de caipiras e de velhos.

Essa ideia ratifica a atitude negativa e até preconceituosa frente à variação na concordância verbal por parte dos estudantes do campo, os quais acreditam não usar as formas não padrão quando a avaliam, mas usam-nas em suas respostas, como é possível notar até este momento, e usaram-nas na entrevista sociolinguística. É interessante

\footnotetext{
${ }^{16}$ Defende-se, neste artigo, a ideia de que o campo não é mais o espaço do atraso porque o espaço urbano tem entrado cada vez mais no rural e o rural, no caso de Tucano-BA, sobretudo, tem sobrevivido no urbano, mostrando a ressignificação dos espaços e a hibridez das culturas (CANCLINI, 1997; GIRARDI, 2008; ARAÚJO, 2011). Ressalta-se, entretanto, que, historicamente, ao campo foram negados direitos básicos como educação, fazendo muito sentido, portanto, a fala da estudante P5RF.
} 
ressaltar que, mesmo de forma preconceituosa, os estudantes de modo geral e, especificamente, os do campo reconhecem que há fatores que condicionam a maneira de falar, como já foi dito em outros momentos. Além do lugar e da escola, nota-se agora a faixa etária, quando diferenciam o falar dos jovens do falar dos velhos. Essa ententimento, porém, não impede que os alunos da zona rural avaliem a variação na concordância verbal como um estereótipo, pois mais forte que ela é o papel da escola na vida de tais estudantes, agindo como uma força que tenta unificar a língua.

Referente às questões e) dos quadros 3 e 4: "O que você acha de falar nós vai?" e "O que você acha de falar eles quer?", os estudantes do campo, como já era esperado por suas reações anteriores à variação na concordância verbal, manifestaram uma atitude negativa, afirmando "[...] que é uma forma muito errada de falá, porque tá tendo uma mistura com plural e singular” (P5RF), o que demonstra uma visão da solidariedade, da relação que deve ser estabelecida entre os sintagmas nominal e verbal.

Os alunos da cidade avaliaram as formas "nós vai" e "eles quer" como erradas, assim como fizeram no momento da entrevista, em que julgaram como "certa" a variante "os ladrões tinham" em detrimento da variante "os ladrão tinha”. No teste de crenças, entretanto, os alunos julgaram como correta a forma não padrão de P4 e se dividiram quanto à de $\mathrm{P} 6$. Nota-se, assim, que quanto ao uso, como visto na discussão da questão 5 do quadro 10 e das questões c) dos quadros 3 e 4, há um consenso, pois afirmam usar as formas não padrão; quanto à avaliação, porém, os estudantes, nos três procedimentos metodológicos (perguntas orais no final da entrevista, teste escrito de crenças linguísticas e teste oral de crenças linguísticas) não têm uma mesma reação, o que pode ser explicado pelo próprio modelo de aferição das reações subjetivas, já que quando as perguntas são feitas oralmente para os estudantes, eles reagem às variantes não padrão negativamente, por conseguirem perceber as diferenças flexionais, mas quando leem, no teste de crenças, para assinalar se "nós é bonito" e "eles quer comida" são frases "certas" ou "erradas" não parecem perceber a ausência de marcas flexionais de plural, o que leva à avaliação dessas formas como corretas. Mesmo parecendo uma contradição, defende-se que essas diferentes avaliações ocorreram por conta das modalidades oral e escrita, o que será possível confirmar ou refutar em uma pesquisa futura, que deve acolher também o continuum de oralidade-letramento (BORTONI-RICARDO, 2004; 2005). Além disso, pode-se atribuir essa diferente avaliação à dificuldade em reconhecer o estigma social da variação na concordância verbal.

Passando às questões g) dos dois últimos: "Você acha que falar nós vai/eles quer tem a ver com o nível de estudo da pessoa? Por quê?", constatou-se que, quanto à P4 e à P6, os estudantes do campo creem que a escolaridade influencia, ao afirmarem: "Sim, porque se estudou é pra aprendê a falá correto, né?" (P5RF) e "Sim, porque quem fala nós vai é quem estudou pouco" (P8RM), demonstrando, novamente, o entendimento de que fatores extralinguísticos condicionam a forma de falar. Por outro lado, os estudantes da cidade se dividem quanto à $\mathrm{P} 4$ e à $\mathrm{P} 6$, não chegando a um consenso se a escolaridade influencia ou não. É válido citar o que afirmou o aluno P3UM, quando perguntado se falar "nós vai/eles quer" se relaciona com o nível de estudo: "Não, porque não vai importar, porque não importa os estudo", manifestando a crença de que falar de um jeito ou de outro não implica o grau de escolarização. 
Quando foram colocadas as últimas questões dos quadros 3 e 4 para os alunos: "Você acha que as pessoas que falam nós vai/eles quer sofrem preconceito? Por quê?", percebeu-se que os participantes desta pesquisa, em geral, acreditam que quem não segue o padrão sofre preconceito, argumentando os estudantes que: "Sim, porque tão falando errado e o povo vai corrigir" (P1UF); "Sim, porque as pessoa diz que é da roça” (P3UM); "Às vezes muitas pessoas tiram sarro [...], porque já existe esse preconceito, já pelo simples fato das pessoas não terem estudado muito, e isso já vem de antes” (P5RF); “Às vezes, porque 'nós vai' é mais do caipira [...] porque vão chamar ele de caipira, porque 'eles quer' vem do caipira" (P6RF); "Sim, porque... porque tá falando errado" (P8RM). Observa-se, nessas passagens, que os estudantes, principalmente os do campo, refletem sobre os possíveis condicionamentos para um falar diferente, avaliando que a escolaridade e o lugar podem influenciá-lo, de modo que o termo caipira utilizado pela P6RF indica as pessoas mais velhas da zona rural.

Realizada esta análise das reações subjetivas dos estudantes pesquisados, a seguir, apresentam-se as considerações finais deste artigo.

\section{CONSIDERAÇÕES FINAIS}

Ao longo deste artigo, foram apresentadas as reações subjetivas dos participantes desta pesquisa a respeito da variação na concordância verbal. Para isso, primeiro foram apresentadas as perguntas metalinguísticas realizadas no final da entrevista sociolinguística e as respostas dos estudantes e, em seguida, os resultados do teste de crenças.

Observou-se que os estudantes do campo se mostraram mais críticos e detentores de uma avaliação sociolinguística mais aflorada, ao reconhecerem, por exemplo, que existe mais de uma forma de falar "certo". Em geral, os estudantes pesquisados reconhecem a forma padrão da concordância verbal, sendo que os da área rural avaliam a não padrão de forma negativa e afirmam que não a usa; os alunos da cidade, por outro lado, asseguram que a usam.

Discutiu-se a avaliação da variação na concordância verbal por meio de testes de crenças e foi constatado que os alunos do campo reforçaram a crença de que não usam a variante não padrão de P4 (primeira pessoa do plural) e P6 (terceira pessoa do plural), ratificando sua atitude negativa frente a essa variante; os alunos da cidade exibiram a crença de que usam a variante não padrão de $\mathrm{P} 4$ e se dividiram quanto à de $\mathrm{P} 6$, avaliando essas formas, em geral, como erradas.

Em resumo, ao serem analisadas as crenças dos estudantes sobre as variantes não padrão da concordância verbal, percebeu-se que as formas não padrão não têm o mesmo valor social para os dois grupos (rural/urbano), pois mesmo julgando-as como erradas, os estudantes da cidade, diferentemente dos do campo, afirmaram usá-las, o que se atribui ao fato de não perceberem o estigma social das formas analisadas, ou seja, não reconhecem que as pessoas que usam as variantes não padrão são tachadas como inferiores e ignorantes.

\section{REFERÊNCIAS}


AGUILERA, Vanderci de Andrade. Crenças e atitudes linguísticas: o que dizem os falantes das capitais brasileiras. Estudos Linguísticos, São Paulo, v. 2, n. 37, p. 105-112, 2008.

ARAÚJO, Giovanna de Aquino Fonseca. Continuidade e descontinuidade no contexto da globalização: um estudo de feiras em Portugal e no Brasil (1986-2007). Tese (Doutorado em História) - Universidade do Minho; Universidade Federal da Bahia, Salvador, 2011.

BAGNO, Marcos. Preconceito linguístico: o que é, como se faz?? 4. ed. São Paulo: Edições Loyola, 2000.

BARBOSA, Juliana Bertucci; CUBA, Daiana Lombardi. Crenças e atitudes linguísticas de alunos do ensino médio em escolas públicas de Uberaba. Todas as letras $Y$, São Paulo, v. 17, n. 1, p. 73-90, 2015.

BARCELOS, Ana Maria Ferreira. Cognição de professores e alunos: tendências recentes na pesquisa de crenças sobre ensino e aprendizagem de língua. In: BARCELOS, Ana Maria Ferreira; ABRHÃO, Maria Helena Vieira (Org.). Crenças e ensino de língua: foco no professor, no aluno e na formação de professores. Campinas: Pontes, 2006, p. 15-42.

BISINOTO, Leila Salomão Jacob. Atitudes sociolinguísticas: efeitos do processo migratório. Campinas: Pontes Editores/RG Editores, 2007.

BORTONI-RICARDO, Stella Maris. Educação em língua materna: a sociolinguística na sala de aula. São Paulo: Parábola Editorial, 2004.

BORTONI-RICARDO, Stella Maris. Nós cheguemu na escola, e agora?: sociolinguística e educação. 2. ed. São Paulo: Parábola Editorial, 2005.

BORTONI-RICARDO, Stella Maris. A concordância verbal em português: um estudo de sua significação social. In: VOTRE, Sebastião; RONCARATI, Cláudia (Org.). Anthony Julius Naro e a lingüistica no Brasil: uma homenagem acadêmica. Rio de Janeiro: 7Letras, 2008, p. 362-380.

CANCLINI, Néstor García. Culturas híbridas, poderes oblíquos. In: CANCLINI, Néstor García. Culturas híbridas: estratégias para entrar e sair da modernidade. Tradução de Ana Regina Lessa e Heloísa Pezza Cintrão. São Paulo: EDUSP, 1997, p.283-350.

CYRANKA, Lucia Furtado Mendonça. Atitudes linguísticas de alunos de escolas públicas de Juiz. de Fora-MG. Tese (Doutorado em Linguística) - Instituto de Letras, Universidade Federal Fluminense, Niterói, 2007.

FERMINIO, Patrícia Corrêa. A variação na concordância verbal de terceira pessoa do plural em textos escritos e orais de alunos das séries finais do ensino fundamental da rede pública de ensino de 
Florianópolis e Itajaí. Dissertação (Mestrado) - Universidade Federal de Santa Catarina, Centro de Comunicação e Expressão, Programá de Pós-Graduação em Linguística, 2017.

GIRARDI, Eduardo Paulon. Proposição teórico-metodológica de uma cartografia geográfica crítica e sua aplicação no desenvolvimento do atlas da questão agrária brasileira. $347 \mathrm{f}$. Tese (doutorado) Universidade Estadual Paulista, Faculdade de Ciências e Tecnologia, 2008.

LABOV, William. Padrões sociolinguísticos. Trad.: M. Bagno, M. M. P. Scherre, C. R. Cardoso. São Paulo: Parábola Editorial, 2008[1972].

LAMBERT, William; LAMBERT, Wallace. Psicologia social. 3. ed. Rio de Janeiro: Zahar, 1968.

MARINE, T. de C; BARBOSA, J. B. Crenças linguisticas de alunos do PROFLETRAS de universidades no Triângulo Mineiro. Porto Alegre, v. 10, n. 1, p. 361-379, 2017.

MIRANDA, Antonio Luiz Alencar. Crenças, atitudes e usos variáveis da concordância verbal com o pronome tu. Tese (Doutorado) - Universidade Federal do Rio de Janeiro, Faculdade de Letras, Programa de Pós-Graduação em Linguística, 2014.

OUSHIRO, Lívia. Identidade na pluralidade: avaliação, produção e percep̧̧ão linguística na cidade de São Paulo. Tese de Doutorado. Universidade de São Paulo, São Paulo, 2015.

SABADIN, Marlene Neri. Crencas e atitudes linguísticas: aspectos da realidade na tríplice fronteira. Tese (doutorado) - Universidade Federal da Bahia, Instituto de Letras, Salvador, 2013.

SANTOS, Emmanoel. Certo ou errado?: atitudes e crenças no ensino da lingua portuguesa. Rio de Janeiro: Graphia, 1996.

SOUSA, Nilton Carlos Carmo. A percepção da concordância verbal no continuum rural-urbano: uma análise sociolinguistica da fala de estudantes do município de Tucano- $B A$. Dissertação (mestrado) - Universidade Estadual de Feira de Santana, Programa de Pós-Graduação em Estudos Linguísticos, Feira de Santana, 2019.

WEINREICH, Uriel; LABOV, William; HERZOG, Marvin. Fundamentos empíricos para uma teoria da mudança linguística. Tradução: Marcos Bagno; revisão técnica: Carlos Alberto Faraco; posfácio: Maria da Conceição Paiva e Maria Eugênia L. Duarte. São Paulo: Parábola Editorial, 2006[1968]. 